Research Square
Preprints are preliminary reports that have not undergone peer review.

They should not be considered conclusive, used to inform clinical practice, or referenced by the media as validated information.

\title{
Investigation on the Mental Health of Healthcare Workers for Aid in Hu Bei Province During the Outbreak of Covid-19 Based on the Network Survey
}

\author{
Peng Zhpu \\ Sichuan University West China Hospital \\ Na Du ( 13920785057@163.com) \\ The Fourth People's Hospital of Chengdu \\ Yingjie OuYang \\ the Fourth People's Hospital of Chengdu
}

\section{Research}

Keywords: mental health, healthcare workers, SRSS, GAD-7, PHQ-9, COVID-19

Posted Date: June 11th, 2020

DOI: https://doi.org/10.21203/rs.3.rs-34118/v1

License: () (i) This work is licensed under a Creative Commons Attribution 4.0 International License. Read Full License 


\section{Abstract}

Background:The objective of this study isto explore the mental health of healthcare workers went to Hubei for assistance during the outbreak of COVID-19.A total of 210 medical staff who traveled to Hubei Province for assistance in the first time completed the online questionnaire, including the Sleep SelfAssessment Scale (SRSS), Generalized Anxiety Scale (GAD-7), and 9-item patient health questionnaire (PHQ-9).

Results:The average score of the SRSS of all the subjects $₫ 25.13 \pm 6.41 \rrbracket$ was significantly higher than the national norm $\varangle 22.14 \pm 5.48 \otimes(p<0.001)$. The average score of the GAD-7 of all subjects $\varangle 12.37 \pm 4.89 \llbracket$ was at the level of moderate anxiety, while the average score of the PHQ- 9 of them $₫ 8.90 \pm 5.42 \varangle$ was at the level of mild depression. The scores of SRSS and GAD-7 of all males $₫ 26.60 \pm 6.38,14.45 \pm 3.80 \rrbracket$ were significantly higher than those of females $₫ 23.67 \pm 6.12$, $10.28 \pm 4.99 \rrbracket(p<0.01)$.

Conclusions: In this epidemic, the sleep quality of frontline medical staff in Hubei Province is poor, and the symptoms of anxiety and depression are common, while the anxiety is more prominent. Among them, the sleep and anxiety symptoms of males are more obvious than that of women, suggesting that we should pay attention to the psychological support of male doctors and nurses and provide them with appropriate psychological decompression training.

\section{Background}

The COVID-19 beginning in late 2019 has spread for almost four months. This calamity drove to the execution of the city closure policy in Hubei Province, and the worst-hit areas, Wuhan, is a city that everyone talks approximately. Since the virus is exceedingly contagious and pathogenic, it has caused a particular stun to the general public. In this exceptionally period, when the virus was raging, there was a group of people who were risking infection, applied for providing medical assistance in Hubei Province. For conventional people, they can choose to cancel, delay or alter the way they work, but the healthcare workers choose to take on more heavy work; and fight against danger. In this manner, this group of healthcare specialists in Hubei is not only under work pressure but also may be under tremendous mental pressure.

Relevant researches have found that during the SARS flare-up in 2003, front-line healthcare workers experienced substantial mental pressure and work pressure[1-3].Simultaneously ,during the outbreak of 2015 Middle East respiratory syndrome(MERS) Co-V, the hospital workers in South Korea also experienced various negative emotions and stress[4]. Other examples include novel swine-origin influenza A (H1N1) that originated in Mexico in 2009, Ebola in Guinea in 2013, the front-line medical workers,were reported have experienced a great deal of emotional stress related to their work[5].However, in the outbreak of COVID-19 in Hubei Province, an expansive number of healthcare workers from other provinces and cities went to support, and they stationed at the source nearly two months, and long-term separation from family members and adaptation to new places may further increase their pressure because being assigned to unfamiliar work groups could reduce collegial interaction[6]. What's more, the related report has suggested that the group of healthcare workers were at the forefront of the 'special battle' against infectious diseases, placing them at a greater risk of infection[7]. Therefore, the potential risk may aggravate their mental burden further.

The latest report on COVID-19 has discovered that front-line healthcare workers are vulnerable to the emotional impact of COVID-19[8]. But up to now, there is little information of the mental health of the healthcare workers went to Hubei for assistance. To understand the mental health of the above-mentioned particular groups, this study intends to utilize them as a research participant to analyze the mental health status of this group in order to explore the psychological structure characteristics of this particular group. Furthermore, we intend to provide guidance for their intervention support programs after returning.

\section{Method}

\section{Subjects}

From January to February 2020, the healthcare workers sent to Hubei Province for medical assistance from exterior Hubei Area were selected as the objects of the investigation. The questionnaire was distributed to these healthcare workers in the form of network, and the principle of voluntary filling was adopted. The research has got the institutional review board (IRB) approval of West China Hospital. Two hundred twenty questionnaires were sent out in total, 210 qualified questionnaires were recovered, and the recuperation rate of the questionnaire was $95.4 \%$.

\section{Measures}

The research tool (scale) are self-assessment questionnaire, and the following survey items are completed according to the unified guidance, including (1) general situation survey: including the gender, age, education background, marriage, occupation, education level. (2) Self-Rating Scale of Sleep(SRSS) [9]: it is composed of 10 items, 1-5 points score each item, and the final total score is the sum of the scores of each item, and the total score range is $10-50$ points. The higher score, the more serious the sleep problem. The national norm score of the scale is $22.14 \pm 5.48$ [10]. (3) Generalized Anxiety Scale(GAD-7) [11]: it consists of 7 items, each item is scored by $0-3$ points, and the total score range is $0-21$ points. Among them, $0-4$ points were no anxiety; $5-9$ points were mild anxiety; 10-14 points were moderate anxiety; 15-21 points were severe anxiety. (4) 9-item patient health questionnaire (PHQ-9) [12]: it is composed of nine items, $0-3$ points score each item, and the total score range is $0-27$ points. Among them, $0-4$ points were no depression; 5-9 points were mild depression; 10-14 points were moderate depression; 15-19 points were moderate and severe depression; 20-27 points were severe depression.

\section{- Statistical analyses}

Descriptive statistics were computed for all variables. The mean scores were then used for comparison among groups using T-test statistics. A P value of < 0.05 was used for statistical significance testing. 


\section{Results}

\subsection{General information on healthcare workers aiding Hubei (see Table 1 below).}

There were 210 healthcare workers in Hubei Province, including 105 males and 105 females. According to the occupational situation, 147 nurses, accounting for $70 \% ; 63$ doctors, accounting for $30 \%$. The age range of them is $23-40$ years old, with an average of $30.47 \pm 4.53$ years. Among them, education background is as follows: secondary school 14 , accounting for $6.7 \%$; junior college 77 , accounting for $36.7 \%$; undergraduate 105 , accounting for $50 \%$; graduate 14 , accounting for $6.7 \%$. The marriage situation is as follows: 98 unmarried people, accounting for $46.7 \%$; 112 married people, accounting for $53.3 \%$. The working years of all subjects ranged from 2 to 20 years, with an average of $8.61 \pm 4.37$ years.

After grouping all subjects according to different genders or occupations, and comparing their average age and working years, it was found that the average age of men was higher than that of women $(t=5.456, P<0.001)$, the working years were longer $(t=2.890, P=0.004)$, the average age of doctors was higher than that of nurses $(t=10.159, P<0.001)$, and the working years were longer $(t=6.780, P<0.001)$.

Table 1

Comparative Analysis of age and working years according to gender and occupation groups

\begin{tabular}{|llll|}
\hline Project & \multicolumn{2}{l}{ Gender classification } & T value \\
\cline { 2 - 3 } & Male $(\mathbf{n}=105)$ & Female $(\mathbf{n = 1 0 5})$ & \\
\hline Average age & $32.07 \pm 4.30$ & $28.87 \pm 4.20$ & $5.456^{\mathrm{b}}$ \\
\hline Working years & $9.47 \pm 3.42$ & $7.75 \pm 5.02$ & $2.890^{\mathrm{a}}$ \\
\hline Project & Occupation Classification & T value \\
\cline { 2 - 3 } & Doctor $(n=63)$ & Nurse $(n=147)$ & \\
\hline Average age & $34.44 \pm 3.33$ & $28.76 \pm 3.87$ & $10.159^{\mathrm{b}}$ \\
\hline Working years & $11.44 \pm 4.06$ & $7.39 \pm 3.92$ & $6.780^{\mathrm{b}}$ \\
\hline a:P<0.01; $\mathrm{b}: P<0.001$ & & \\
\hline
\end{tabular}

3.2 Investigation results of GAD-7 and PHQ-9 for healthcare workers in Hubei Province (see Table 2 below)

We can see from the table that the average score of anxiety scale of healthcare workers is at the level of moderate anxiety, while the average score of depression scale is at the level of mild depression. Among them, the proportion of people with moderate anxiety level is the highest, accounting for $43.3 \%$; while the proportion of people with moderate depression level is the highest, accounting for $35.7 \%$.

Table 2

the scores of GAD-7 and PHQ-9 of healthcare workers in Hubei Province

\begin{tabular}{|c|c|c|c|c|c|c|c|c|c|c|c|}
\hline \multirow{3}{*}{$\begin{array}{l}\text { Survey } \\
\text { items }\end{array}$} & \multirow{3}{*}{$\begin{array}{l}\text { Average } \\
\text { score }\end{array}$} & \multicolumn{10}{|l|}{ Severity } \\
\hline & & \multicolumn{2}{|l|}{ No } & \multicolumn{2}{|l|}{ Light } & \multicolumn{2}{|c|}{ Moderate } & \multicolumn{2}{|c|}{ Moderate severe } & \multicolumn{2}{|l|}{ Severe } \\
\hline & & Number & $\begin{array}{l}\text { Percentage } \\
\text { (\%) }\end{array}$ & Number & $\begin{array}{l}\text { Percentage } \\
\text { (\%) }\end{array}$ & Number & $\begin{array}{l}\text { Percentage } \\
(\%)\end{array}$ & Number & $\begin{array}{l}\text { Percentage } \\
(\%)\end{array}$ & Number & $\begin{array}{l}\text { Per } \\
\text { (\%) }\end{array}$ \\
\hline GAD-7 & $\begin{array}{l}12.37 \pm \\
4.89\end{array}$ & 19 & 9.0 & 30 & 14.3 & 91 & 43.3 & - & - & 70 & 33. \\
\hline PHQ-9 & $\begin{array}{l}8.90 \pm \\
5.42\end{array}$ & 59 & 28.1 & 47 & 22.4 & 75 & 35.7 & 23 & 11.0 & 6 & 2.9 \\
\hline
\end{tabular}

3.3 Comparison of scores of SRSS, GAD-7 and PHQ-9 of healthcare workers in Hubei Province under different genders and occupational categories (see Table 3 below)

The results showed that the score of male sleep scale was significantly higher than that of female $(t=3.397$, $P=0.001)$, i.e. the sleep quality of male was worse than that of the female; the score of male anxiety scale was significantly higher than that of female $(t=6.832, P<0.001)$, i.e. the anxiety level of the male was higher than that of the female; however, there was no significant difference in the score of depression scale between male and female $(t=1.611, p=$ 0.109)【

The results showed that there was no significant difference in sleep quality, anxiety level and depression level between doctors and nurses. 
Table 3

Comparative Analysis of SRSS,GAD-7 and PHQ-9 according to gender and occupation groups

\begin{tabular}{|llll|}
\hline Project & \multicolumn{2}{l}{ Gender classification } & T value \\
\cline { 2 - 3 } & Male $(n=105)$ & Female $(n=105)$ & \\
\hline SRSS & $26.60 \pm 6.38$ & $23.67 \pm 6.12$ & $3.397^{\mathrm{a}}$ \\
GAD-7 & $14.45 \pm 3.80$ & $10.28 \pm 4.99$ & $6.832^{\mathrm{b}}$ \\
PHQ-9 & $9.50 \pm 5.37$ & $8.30 \pm 5.42$ & 1.611 \\
\hline Project & Occupation Classification & T value \\
\cline { 2 - 3 } & Doctor $(n=63)$ & Nurse $(n=147)$ & \\
\hline SRSS & $24.22 \pm 4.82$ & $25.52 \pm 6.96$ & 1.351 \\
\hline GAD-7 & $13.16 \pm 3.25$ & $12.03 \pm 5.42$ & 1.540 \\
PHQ-9 & $8.06 \pm 4.69$ & $9.27 \pm 5.68$ & 1.477 \\
\hline a:P<0.01; b:P $P<0.001$ & & \\
\hline
\end{tabular}

\section{Discussion}

Due to the sudden outbreak, rapid contagious, and the lack of anti-virus vaccines and medicine, it is inevitable that healthcare workers participating in clinical first-line treatment will sustain enormous pressure and expose themselves to hazard. However, healthcare workers from other provinces and cities have left their hometown and come to a particular area. They work in conjunction with the local healthcare workers in the anti-epidemic work. Therefore, they will moreover confront the corresponding pressure. In order to understand the mental health status of the particular population, this study uses the way of network questionnaire to investigate their sleep quality, anxiety level and depression level in this part of Hubei Province, to provide guidance on how to carry out the corresponding psychological intervention after their return journey.

This study showed that the sleep quality of all the healthcare workers was significantly worse than that of the ordinary people, which indicated that the healthcare workers in Hubei Province could not have a good rest due to the limited accommodation conditions and heavy work tasks during the working period. Even some people might have some sleep disorders. According to the investigation of the first-line healthcare workers during the SARS outbreak in $2003,26.62 \%$ of them suffered from insomnia [13]. According to media reports, we can see that due to the shortage of protective materials, in arrange to save materials, medical personnel need to work continuously for 6-7 hours after wearing protective clothing. This kind of high-intensity work would inevitably lead to excessive exhaustion of energy and pressure of the human body, and under the excessive pressure, the main performance of the human body may be sleep problems. Therefore, for these particular groups, the government should give them appropriate leaving system after their return to ensure that everyone has enough sleep, to help them to adjust their daily life and return to regular work.

Through the analysis of the scores of anxiety and depression self-assessment scale of all healthcare workers, it can be found that there are some anxiety and depression in healthcare workers, and the performance of anxiety is more prominent than depression. About $14.3 \%$ of them are at the level of mild anxiety, $43.3 \%$ are at the level of moderate anxiety, and $33.3 \%$ are at the level of severe anxiety. It can be seen that anxiety symptoms are the most common and prominent manifestation of the aid workers. Some scholars have believed that the psychological reactions of individuals after encountering stress events mainly include depression and anxiety [14, 15]. However, our healthcare workers in Hubei Province have to face not only the highly infectious new COVID-19 but also heavy physical consumption and enormous mental pressure every day. In this manner, anxiety and depression are inevitable. As this study found, approximately $35.7 \%$ of the people are moreover at the level of moderate depression. As Tian et al. [13] analyzed when investigating the mental health level of healthcare workers on the front-line of SARS prevention and treatment, these front-line workers must treat and care patients in the condition of wearing protective clothing, gloves, hats, masks and eye masks, and must receive isolation observation after work, which will increase their mental pressure. Besides, since few healthcare workers in Hubei Province have ever been exposed to the prevention and control of infectious diseases, they may also have some deficiencies in the knowledge and skills related to epidemic prevention and control. The temporary multiple training tasks before entering the front-line will also increase their mental pressure. During the period of aiding Hubei, the time of communication with family and companions will be significantly reduced, which will further diminish their sources of social support, resulting in an increase in the probability of mental problems. Besides, according to the report of the aid specialists in Hubei Province, they are all temporarily living in the hotels designated by the government, one person living in one room, and they need to avoid gathering as much as possible after returning from work. Therefore, most people can only live alone in a narrow space, and this monotonous living environment will inevitably lead to inevitable depression. Therefore, the above results suggest that we need to pay more attention to the mental health level of healthcare workers in Hubei Province, and may need to provide them with appropriate relaxation training and positive suggestion training, so as to assist them better through the involvement of Hubei Province.

Because there are some differences in the psychological characteristics and expression ways between men and women, this study compared and analyzed the sleep, anxiety and depression scale of healthcare workers in Hubei Province according to different genders. After analysis, we found relatively extraordinary results that the sleep quality of men was worse than that of women, and their anxiety level was higher. From the previous research results, we found that in the face of the SARS outbreak, the anxiety severity of women in the population is generally higher than that of men [16]. Wang and others also found that women healthcare workers may be more prone to anxiety and depression than men in mental status changes [17]. However, our research results 
are different from others, and the specific situation needs specific analysis. We can see that the previous research object is the general public or the local healthcare workers, and no one has analyzed the mental health of the particular group of healthcare workers aiding Wuhan. The reason for the male sleep deviation and massive anxiety maybe, on the one hand, due to the fact that the age of male aid workers is generally older, their physical strength and energy recovery level will not be as fast as that of young women, so they are more prone to fatigue and insomnia; on the other hand, more of these men have already married, so long-term absence from home and less communication with spouse or children will make it difficult for them to release the negative emotions caused by stress expeditiously, in the case of chronic stress. There is bound to be an increment in anxiety levels.Additionally,since numerous women belong to the nurse group, and they are youthful, their estrogen level secretion is in an intense period, so it is also a protective factor for their emotions. Women are more inclined to express their emotions at any time, so less negative emotions will be overstocked. From the above results, we can see that in the past, we need to pay more attention to the mental wellbeing of female health workers. However, male health workers may also require psychological counselling, and learn to actively express emotions, in order to diminish their anxiety level further.

\section{Conclusions}

Finally, through this study, we can discover that there is a specific lopsidedness in mental health level and sleep of healthcare workers in Hubei Province. Male anxiety performance and sleep disorders may be more prominent, which suggests that we may also need to provide appropriate psychological intervention for these particular groups, so as to assist them to put into their original working position after returning from Hubei Province.

\section{Declarations}

\section{Ethics approval and consent to participate:}

The research has got the institutional review board (IRB) approval of West China Hospital, and all the subjects were recruited in the principle of voluntary.

\section{Consent for publication:}

Not applicable.

\section{Availability of data and materials:}

The datasets used and/or analysed during the current study are available from the corresponding author on reasonable request.

\section{Competing interests:}

The authors declare that they have no competing interests.

\section{Funding:}

Not applicable

\section{Authors' contributions:}

Peng Zhou was a major contributor in writing the manuscript, and he also was responsible for recruited the subjects in this survey. Na Du was responsible for the corresponding part of this manuscript, and she designed the investigation. Yingjie OuYang collected and analyzed the data, and she also translated this article to English. All authors read and approved the final manuscript.

\section{Acknowledgements:}

We sincerely thank all the healthcare workers who took part in our survey for their assistance in this study.

\section{References}

1. Maunder R, Hunter J, Vincent L, et al. The immediate psychological and occupational impact of the 2003 SARS outbreak in a teaching hospital. Can Med Assoc J. 2003;168(10):1245-51.

2. Maunder RG, Lancee WJ, Rourke S, et al. Factors associated with the psychological impact of severe acute respiratory syndrome on nurses and other hospital workers in Toronto. Psychosomatic Med. 2004;66(6):938-42.

3. Wong TW, Yau JK, Chan CL, et al. The psychological impact of severe acute respiratory syndrome outbreak on healthcare workers in emergency departments and how they cope. Eur J Emerg Med. 2005;12(1):13-8.

4. Heejung S, Wang JL, Hyun SK, et al. Examination of hospital workers' emotional responses to an infectious disease outbreak: lessons from the 2015 MERS Co-V outbreak in South Korea. Disaster Med Public Health Prep. 2019;13(3):504-10.

5. Wheeler HH. A review of nurse occupational stress research: 1. BJN. 1997;6(11):642-5. https://doi.org/10.12968/bjon.1997.6.11.642. 
6. Goldbloom DS, Petryshen PM. The experience of the 2003 SARS outbreak as a traumatic stress among frontline healthcare workers in Toronto: Lessons learned. Edited by McLean AR, May RM, Pattison J, et al, Oxford University Press Publishing; 2005.

7. Grobler L, Mehtar S, Dheda K, et al. The epidemiology of tuberculosis in health care workers in South Africa: a systematic review. BMC Health Serv Res. 2016;16(1):416.

8. Xiang YT, Yang Y, Li W, et al. Timely mental health care for the 2019 novel coronavirus outbreak is urgently needed. Lancet Psychiatry. 2020;7:228-9.

9. Li JM. Seff-Rating Scale of Sleep(SRSS). China journal of health psychology. 2012;20(12):1851.

10. Li JM, Yin SF, Duan JX, et al. Analysis rating of sleep state of 13273 normal persons. Health psychology journal. 2000;8(3):351-3.

11. He XX, Li CB, Qian J, et al. Reliability and validity of a generalized anxiety disorder scale in general hospital outpatients. Shanghai archives of psychiatry. 2010;22(4):200-3.

12. Martin A, Rief W, Klaiberg A. et a1. Validity of the brief patient health questionnaire mood scale(PHQ-9)in the general population. Gen Hosp Psychiat. 2006;28(1):71-7.

13. Tian $X Y$, Wang $X H$, Li YQ, et al. The immediate psychological and behavioral response of health workers from SARS treatment specific hospitals. Chinese general practice. 2003;6(7):595-7.

14. Huang L, Yang TZ, Ji ZM. Applicability of the positive and negative affect scale in Chinese. China journal of health psychology. 2003;17(1):54-6.

15. Hardy GE, Woods D, Wall TD. The impact of psychological distress on absence from work. J Appl Psychol. 2003;88(2):306-14.

16. Wang XY, Jin KX, Wang QC, et al. Survey of different crowd psychological status during SARS. Health psychology journal. 2003;11(6):441-2.

17. Wang LW, Yang LH, Chen XB, et al. The investigation of psychological status of medical staff during epidemic outbreak stage of SARS in Wuhan. Chinese journal of behavioral medical science. 2003;12(5):76-8. 